\title{
INVESTIGATION AND TREATMENT OF AIR POLLUTION FROM INCENSE BURNING IN VIETNAM
}

\author{
Nguyen Thi Thuy ${ }^{1,2}$, Tran Tien Khoi ${ }^{1,2}$, Dang Thi Anh Thu ${ }^{2,3}$, Vo Thi Thanh Thuy ${ }^{2,3}$, \\ Hoang Cong Anh Duy ${ }^{2,3}$, Lam Pham Thanh Hien ${ }^{2,3}$, and Nguyen Nhat Huy 2,3* \\ ${ }^{1}$ Department of Environmental Engineering, International University, Thu Duc City, Ho Chi Minh City \\ ${ }^{2}$ Vietnam National University Ho Chi Minh City, Thu Duc City, Ho Chi Minh City, Vietnam \\ ${ }^{3}$ Faculty of Environment and Natural Resources, Ho Chi Minh City University of Technology (HCMUT), \\ Ho Chi Minh City, Vietnam, Tel: +84 901964 985, e-mail: nnhuy@ @omut.edu.vn
}

Received Date: February 12, 2020; Revised Date: October 26, 2020; Acceptance Date: February 17, 2021

\begin{abstract}
Indoor air pollution caused by combustion is a common problem in low-and middle-income countries which negatively affects human health. In Asian countries, burning incense in temples, pagodas, or residences is popular. This study consists of three contents (i) monitoring air quality parameters, including total volatile organic compounds (TVOCs), particulate matter (i.e. PM10 and PM2.5), and $\mathrm{CO}_{2}$ concentration in five pagodas in Ho Chi Minh City and Binh Duong province; (ii) determining air pollutants concentration generated by incense burning in room; and (iii) investigating incense smoke removal ability of photocatalytic devices. The results showed that the average air pollutants concentration in the pagodas was $625-1,108 \mathrm{ppb}$ of TVOCs, $1,935-2,967 \mathrm{ppm}$ of $\mathrm{CO}_{2}, 1,175-2,137 \mu \mathrm{g} / \mathrm{m}^{3}$ of PM2.5, and $1,589-2,871 \mu \mathrm{g} / \mathrm{m}^{3}$ of PM10 in which TVOCs, PM2.5, and PM10 were presented at the threshold of direct impact on human health. Burning seven types of incense in a room revealed that the cinnamon incense smoke contained the highest concentration of TVOCs. Using photocatalytic devices for incense smoke treatment showed that the photocatalyst provided the best removal efficiency of VOCs (48.13\%) was zinc salt-impregnated titanium dioxide with $\mathrm{Zn} / \mathrm{Ti}$ molar ratio of $0.5 \%$ and calcined at $500{ }^{\circ} \mathrm{C}$. This result was initially successful in finding a way to low down VOCs concentration generated from incensation to allowable level (490 ppb).
\end{abstract}

Keywords: Incense, Indoor air pollution, Photocatalysis, PM10, PM2.5, VOCs

\section{Introduction}

Burning of incense is commonly found in temples, pagodas, and residences due to the religious purpose and/or for generating aroma smell. Incense rituals are practices of many Asians, especially those with Buddhist culture in Southeast Asia. Incense has entered the cultural life of the Vietnamese people and lit incense on ancestor altars is a beauty of traditional culture indispensable in the occasion of anniversaries and Tet holidays. 
Incense is made of different ingredients, including resins, spices, aromatic wood and bark, herbs, seeds, roots, flowers, essential oils, and synthetic substitute chemicals [1]. Incense can appear in the form of sticks, joss sticks, cones, coils, powders, rope, rocks/charcoal, and smudge bundles [2]. Currently, there are many types of incense in the Vietnam market, which are suitable for different purposes. Burning incense is a type of smoldering combustion of biomass burning which is at low temperature without flame, and incomplete. Due to this condition, a large number of pollutants in gaseous and particulate forms were generated [3].

These harmful air pollutants can be methane, methanol, ethylene, ammonia, and formaldehyde [4]. Other dangerous volatile organic compounds (VOCs) including benzene, 1,3 butadiene, and furan, semi VOC (SVOC) and polycyclic aromatic hydrocarbons (PAHs) were also created during incomplete burning of incense [5]. The aerodynamic diameter of dust particles emitted from the combustion is usually less than $1 \mu \mathrm{m}$ and these particles may adsorb toxic substances such as carboxylic acids, PAHs, oxidized PAHs, azaarenes, aldehydes, compound's allergen aromatic rings, organic ingredients, and heavy metals [4, 5]. Air pollutants emitted by burning different types of incense were investigated in some previous studies. In 2002, Jetter et al. [2] measured the rate and emission factor of particulate matter from 23 types of incense. By using an indoor air quality model with a room of $30 \mathrm{~m}^{3}, \mathrm{PM} 2.5$ concentration was estimated at $0.081-10.5 \mathrm{mg} / \mathrm{m}^{3}$. In 2004 , Lee and Wang [6] tested the pollutants emission from either burning simutaneously three sticks (for traditional types) or one stick (for aromatic types) from ten types of incense in a chamber of $18.36 \mathrm{~m}^{3}$. The ranges of PM2.5 and PM10 concentrations during burning three stickes were $0.008-18.264 \mathrm{mg} / \mathrm{m}^{3}$ and $0.01-20.877 \mathrm{mg} / \mathrm{m}^{3}$, respectively, while burning one stick emitted PM2.5 and PM10 at 0.023$2.411 \mathrm{mg} / \mathrm{m}^{3}$ and $0.027-2.827 \mathrm{mg} / \mathrm{m}^{3}$, respectively. The emission of other pollutants was also recorded at 0.86-38.77 ppm for $\mathrm{CO}, 9.9-427.2 \mathrm{ppb}$ for $\mathrm{NO}_{\mathrm{x}}, 1.11-4.57 \mathrm{ppm}$ for $\mathrm{CH}_{4}$, 0.04-1.64 ppm for non-methane hydrocarbon (NMHC), and 550-938 ppm for $\mathrm{CO}_{2}$. In 2016, Lui et al. [7] measured the emission of PM2.5 in an enclosed chamber of $19.1 \mathrm{~m}^{3}$ from burning five types of incense in which PM2.5 appeared at 0.55 to $1.55 \mathrm{mg} / \mathrm{m}^{3}$. More recently, [8] investigated carbonyl emission profile by burning nine incense stick types, and found the most abundant compounds were propionaldehyde, acetaldehyde, acetone and HCHO in which $\mathrm{HCHO}$ ranged from 0.0467 to $0.597 \mathrm{mg} / \mathrm{m}^{3}$.

The levels of incense related pollutants at different temples were also monitored. Wang et al. [9] measured the concentrations of PM10, PM2.5, VOCs, carbonyl compounds, CO, $\mathrm{NO}_{x}, \mathrm{CH}_{4}, \mathrm{NMHC}$, organic carbon, elemental carbon, and inorganic ions at two temples in Hong Kong. The authors found that PM2.5 and PM10 appeared at $0.1-1.3$ and $0.14-1.5 \mathrm{mg} / \mathrm{m}^{3}$, respectively. Beside, 38 VOC species were ranged from 9.8 to $870 \mu \mathrm{g} / \mathrm{m}^{3}$ in which $\mathrm{HCHO}$ and acrolein were found at the levels exceeded World Health Organization (WHO) air quality standard. In other studies conducted in Thailand, benzene, 1, 3-butadiene and PAHs were found at $98.82 \mu \mathrm{g} / \mathrm{m}^{3}, 10.46 \mu \mathrm{g} / \mathrm{m}^{3}$ and $18.02 \mathrm{ng} / \mathrm{m}^{3}$, respectively, at three temples [10], and PM2.5 and PAH were at $0.625 \mathrm{mg} / \mathrm{m}^{3}$ and $90 \mathrm{ng} / \mathrm{m}^{3}$ in a shrine $(8 \mathrm{~h}$, during Chinese new year) [3]. Assessment of pollution level in terms of HCHO, PM10, 12 kinds of VOCs and TVOC was also conducted around incense burner, worship rooms and outside of three temples located in China 
[11]. The results showed that aldehyde compounds varied strongly from 0.05 to $1.22 \mathrm{mg} / \mathrm{m}^{3}$ in which HCHO was the most abundant. Furtheremore, TVOC reached the highest value at 2.72 $\mathrm{mg} / \mathrm{m}^{3}$ at around incense burners.

Due to their small size, incense smoke particles can penetrate deeply into the lungs and settle in the respiratory system. He et al. [12] also reported the association between incense burning and the risk of hypertensive disorders and blood pressure levels during pregnancy. Zhou et al. [13] claims that burning incenses is higher cytotoxicity and genotoxicity than burning cigarette. Although air pollutants related to incense burning are toxic and dangerous, incensation in Vietnam has not been strictly managed and no document reported about field investigation of contaminants in incense smoke in pagodas and temples can be found. Besides the alarming notification of the possibility of the health effect of incense smoke, advising in reducing the number of incense stick burning appears sparsely. Alhough several techniques such as mechanical and electrical filtration, adsorption, ozonation, photolysis, photocatalytic oxidation and biological processes, and membrane separation were mentioned for indoor air pollution treatment [14], and addition of $\mathrm{CaCO}_{3}$ into raw material for incense production was investigated to reduce PM and PAH emission [15], no technique solution has been specified for incense smoke abatement. Therefore, this study was conducted to provide field data of incense burning generated air pollutants concentration from five pagodas in Ho Chi Minh City and Binh Duong Province. The emission behavior of burning seven types of incense in a non-ventilation room was investigated. Next, a device using different photocatalytic materials was tested for its treatment ability of incense smoke. The results from this study could enrich the data on pollutants emission from incense burning in pagodas in Southeast Asia, raise the alarming notification for health effect from this activity, and suggest a technique solution for incense smoke treatment.

\section{Experiment}

\section{Materials and Apparatus}

Chemicals including $\mathrm{Zn}\left(\mathrm{NO}_{3}\right)_{2} .6 \mathrm{H}_{2} \mathrm{O}, \mathrm{HNO}_{3} 65 \%$, $\mathrm{TiO}_{2}$ powder, $\mathrm{P} 25 \mathrm{TiO}_{2}$, and $\mathrm{NaOH} 99.8 \%$ were purchased at analytical grade. Different types of incense were bought from the Cho Lon market (HCMC, Vietnam). ADDWII - Mobile Nose (Taiwan) is a commercial online air quality monitor (Mobile Nose, Addwii, Taiwan) which was used to measure VOC (ppb), PM2.5 and PM10 $\left(\mu \mathrm{g} / \mathrm{m}^{3}\right), \mathrm{eCO}_{2}(\mathrm{ppm})$, temperature $\left({ }^{\circ} \mathrm{C}\right)$, and humidity $(\%)$. This device was calibrated at Nanoparticle and Air Quality Laboratory (Institute of Environmental Engineering, National Chiao Tung University, Taiwan) before using it in this study. The calibrated sensing ranges of TVOCs and $\mathrm{eCO}_{2}$ were 0-60,000 ppb (an error within $\pm 1 \mathrm{ppb}$ ) and 400-60,000 ppm (an error within $\pm 1 \mathrm{ppm}$ ), respectively. The precision for both PM 2.5 and PM10 was $1 \mu \mathrm{g} / \mathrm{m}^{3}$.

\section{Air Pollutants Monitoring at Pagodas}

The concentration of air pollutants in incense smoke (i.e. VOCs, PM2.5, PM10, and eCO 2 ) were monitored at five pagodas randomly selected in Binh Duong province and Ho Chi Minh City (denoted as P-A, P-B, P-C, P-D, and P-E). The concentration of these pollutants was recorded each $5 \mathrm{~min}$ for a total of 75-100 min per day at each sampling location (i.e. number of 
measurement/day from 15 to 20). The experiments were conducted in the afternoon (4-6 pm.) on the full moon days (e.g. $14^{\text {th }}$ and $15^{\text {th }}$ days) from the beginning of June to the end of October 2018, in Lunar Calender. Depending on different pagodas, the number of measured full moon days (n) was from 2 to 4 . The average ambient temperature and humidity during the measurement periods were $27.4{ }^{\circ} \mathrm{C}$ and $78 \%$ for Pagoda A, $30.3{ }^{\circ} \mathrm{C}$ and $72.8 \%$ for Pagoda B, $29.6{ }^{\circ} \mathrm{C}$ and $72.6 \%$ for Pagoda C, $33.6{ }^{\circ} \mathrm{C}$ and $85.2 \%$ for Pagoda D, $32.5{ }^{\circ} \mathrm{C}$ and $79.5 \%$ for Pagoda E.

For the second phase of monitoring, the pagoda A was selected to find the variation in concentration of the pollutants on different days. The measurement was conducted at the beginning $\left(1^{\text {st }}\right)$, the end $\left(29^{\text {th }}\right.$ and $\left.30^{\text {th }}\right)$ of the month, the full moon $\left(14^{\text {th }}\right.$ and $\left.15^{\text {th }}\right)$ and the weekdays (randomly days). Number of each type of day was from 2 to 4 and there were 15-20 times of measurement within 75-100 min for each day. Average ambient temperature and humidity during this second phase was $30.3 \pm 1.8^{\circ} \mathrm{C}$ and $78.5 \pm 4.3 \%$.

\section{Investigation of Air Pollutants Emission Behavior of Burning Different Types of Incense}

Table 1 shows the name, symbol, and weight of seven types of incense selected for burning in a room. The image of these types of incense is given in Figure $1(\mathrm{a})$. The dimensions $(\mathrm{L} \times \mathrm{W} \times$ $\mathrm{H})$ of the room were $2.2 \times 1.8 \times 3 \mathrm{~m}$. The analytical device for monitoring air pollution parameters was placed at a height of $1.5 \mathrm{~m}$ above the floor and $0.6 \mathrm{~m}$ from burning position as given in Figure 1(b). For the first experiments, one stick or coil of each type of incense was burned and the value of parameters was measured in triplicates every 5 min until one incense was completely burned. The pollutants' concentrations emitted from burning each type of incense were then compared and the type of incense with the highest emission of TVOC was selected for further investigation where three sticks were burned simultaneously for each experiment. During experiment periods, the average temperature and humidity in the room were from $29.6 \pm 0.5^{\circ} \mathrm{C}$ and $71.1 \pm 0.6 \%$.

Table 1. Information about Seven Types of Incense

\begin{tabular}{|c|c|c|c|c|c|}
\hline No. & $\begin{array}{l}\text { Name of } \\
\text { Incense }\end{array}$ & Symbol & Description & \multicolumn{2}{|c|}{ Weight of Incense } \\
\hline 1 & Raw incense & N1 & $\begin{array}{l}\text { Without addition of } \\
\text { perfume and } \\
\text { medicinal materials }\end{array}$ & 1.3627 & $\begin{array}{l}\text { (g/one } \\
\text { stick) }\end{array}$ \\
\hline 2 & Perfume incense & $\mathrm{N} 2$ & Addition of perfume & 1.3692 & $\begin{array}{l}\text { (g/one } \\
\text { stick) }\end{array}$ \\
\hline 3 & $\begin{array}{l}\text { Cinnamon } \\
\text { incense }\end{array}$ & N3 & $\begin{array}{l}\text { Addition of } \\
\text { cinnamon power }\end{array}$ & 1.4336 & $\begin{array}{l}\text { (g/one } \\
\text { stick) }\end{array}$ \\
\hline 4 & $\begin{array}{l}\text { Incense with } \\
\text { curled ash }\end{array}$ & N4 & $\begin{array}{l}\text { Keeping ash, fast- } \\
\text { burning, addition of } \\
\mathrm{H}_{3} \mathrm{PO}_{4}\end{array}$ & 1.2139 & $\begin{array}{l}\text { (g/one } \\
\text { stick) }\end{array}$ \\
\hline
\end{tabular}




\begin{tabular}{clclcc}
\hline No. & \multicolumn{1}{c}{$\begin{array}{c}\text { Name of } \\
\text { Incense }\end{array}$} & Symbol & \multicolumn{1}{c}{ Description } & \multicolumn{2}{c}{ Weight of Incense } \\
\hline 5 & $\begin{array}{l}\text { Agarwood } \\
\text { incense }\end{array}$ & N5 & $\begin{array}{l}\text { Addition of } \\
\text { agarwood powder }\end{array}$ & 1.2474 & $\begin{array}{c}\text { (g/one } \\
\text { stick) }\end{array}$ \\
6 & $\begin{array}{l}\text { Black raw } \\
\text { agarbatti incense }\end{array}$ & N6 & $\begin{array}{l}\text { Addition of coal } \\
\text { powder }\end{array}$ & 1.4434 & $\begin{array}{c}\text { (g/one } \\
\text { stick) } \\
\text { (g/one } \\
\text { coil) }\end{array}$ \\
\hline
\end{tabular}
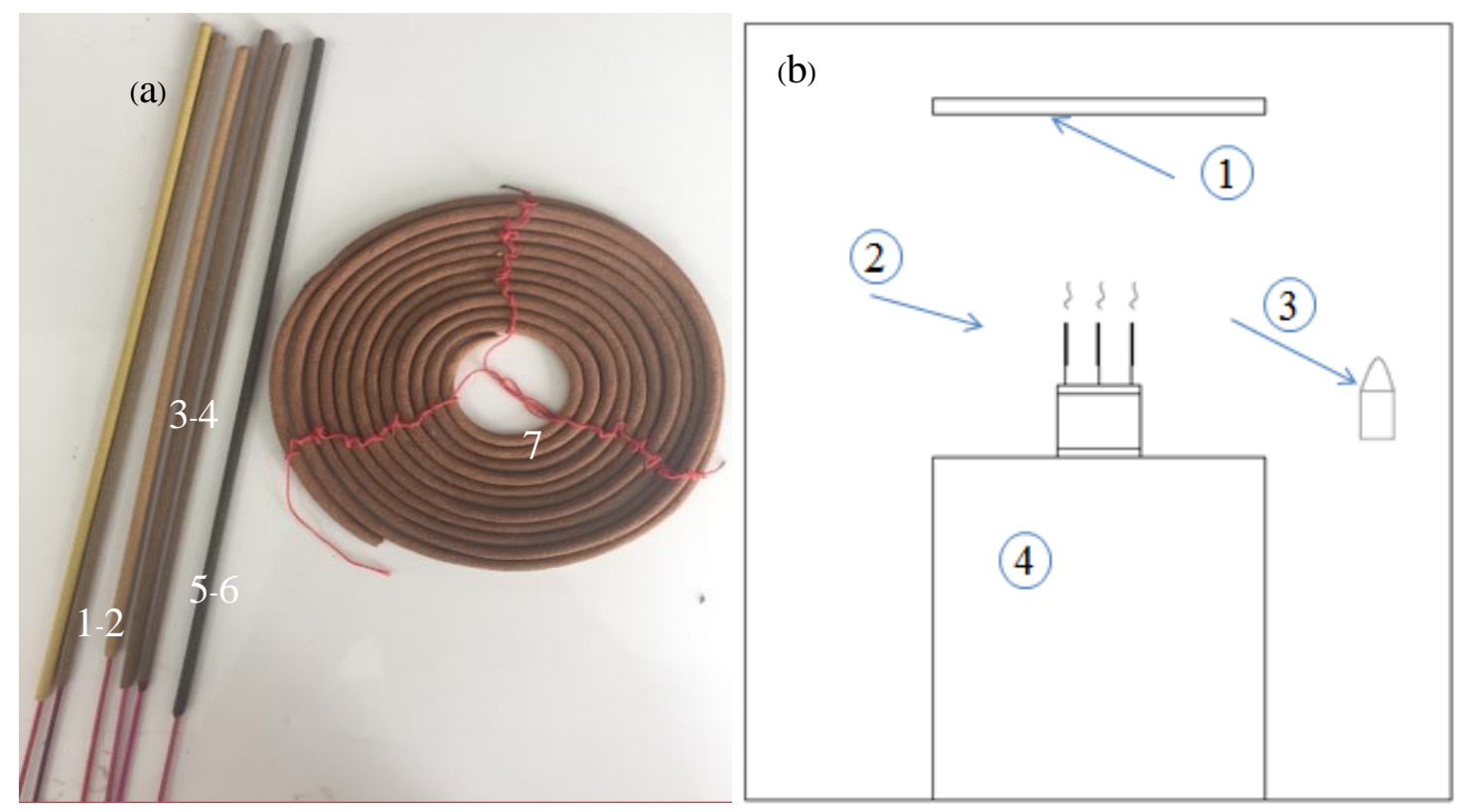

Figure 1. (a) Image of seven types of incense; (b) Room for pollutants emission investigation: (1) light; (2) incense; (3) analytical device; (4) table for placing incense

\section{Treatment of Incense Smoke Using a Photocatalytic Device}

To test the treatment ability of a photocatalytic device, burning of incense was conducted in closed chambers with the dimensions of each chamber $(\mathrm{L} \times \mathrm{W} \times \mathrm{H})$ of $0.85 \times 0.6 \times 0.8 \mathrm{~m}$ (volume of 408 L) (Figure 2). There are a fan and a fluorescence light in each chamber to simulate an indoor enviroment and to create a homogeneous concentration of the pollutants in the chamber.

\section{Synthesis of Photocatalytic Materials}

Titanium dioxide nanotubes (TNT) precursor was synthesized according to the procedure adopted from the reported literature [16-18] using P25 ( $\mathrm{TiO}_{2}$, Degussa) as the precursor via the alkali hydrothermal method and washing at $\mathrm{pH}$ 1.6. The TNTs precursor was used to synthesis photocatalyst followed the impregnation process [19] where $\mathrm{Zn}$ was doped at different $\mathrm{Zn} / \mathrm{Ti}$ 
molar ratios (0.5-1.0\%) and calcined at different temperatures $\left(400\right.$ or $\left.500{ }^{\circ} \mathrm{C}\right)$. These values of $\mathrm{Zn}$ /Ti ratios and temperature of calcination were selected based on the optimum results obtained from Linh et al. [20] who tested the removal efficency of formaldehyde vapor using zinc doped $\mathrm{P} 25$ with $\mathrm{Zn} / \mathrm{Ti}$ ratio from $0.1-10 \%$ and calcinated at the temperature from $300-600{ }^{\circ} \mathrm{C}$. The materials were named as $\mathrm{P} 25500, \mathrm{Zn}_{0.5} / \mathrm{TNT}_{\mathrm{s} 400}, \mathrm{Zn}_{1.0} / \mathrm{TNT}_{4000}, \mathrm{Zn}_{0.5} / \mathrm{TNTs} 500$, and $\mathrm{Zn}_{1.0} / \mathrm{TNT}_{5} 500$.

The glass fiber sheet was prepared at the area equal to the inner surface of the stainless cylinder (with diameter of 42, 49, 90 or $60 \mathrm{~mm}$ and length of $400 \mathrm{~mm}$ ), and coated with the photocatalyst by dip coating method. Firstly, the photocatalyst with the required mass was added in an erlen contained $37 \mathrm{~mL}$ DI water. This solution was then sonicated for $30 \mathrm{~min}$. The fiber sheet was immersed in the solution and then dried for $20 \mathrm{~min}$ at $120^{\circ} \mathrm{C}$. The photocatalyst loaded sheet was then pasted on the inner surface of the stainless cylinder.

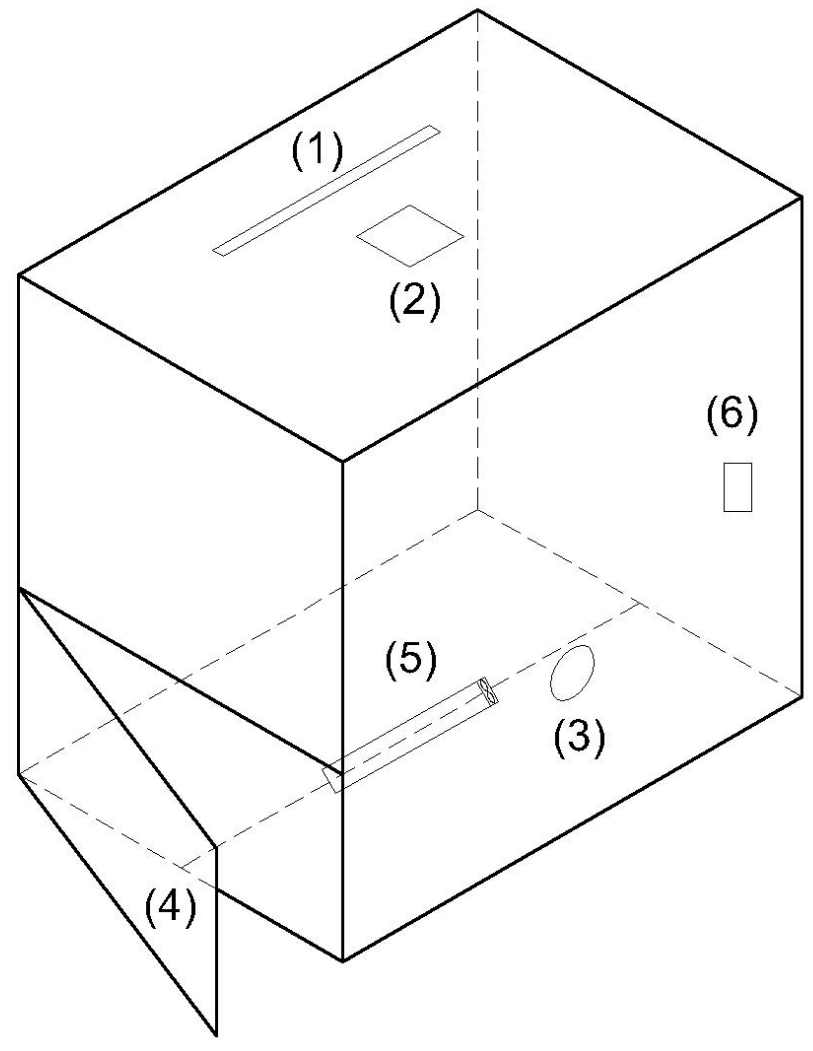

Figure 2. Closed chamber for testing treatment ability of photocatalytic device: (1) light, (2) fan, (3) sampling door, (4) chamber door, (5) photocatalytic device, and (6) measuring device

\section{Photocatalytic Treatment Device}

A photocatalytic treatment device was designed as given in Figures 3(a) while a real picture of the devices can be found in Figure 3(b). The device included a fan (1), a UV-A lamp (2), a photocatalytic coated glass fiber sheet (3), and a cylindrical stainless steel tube (4) with $400 \mathrm{~mm}$ in length. 

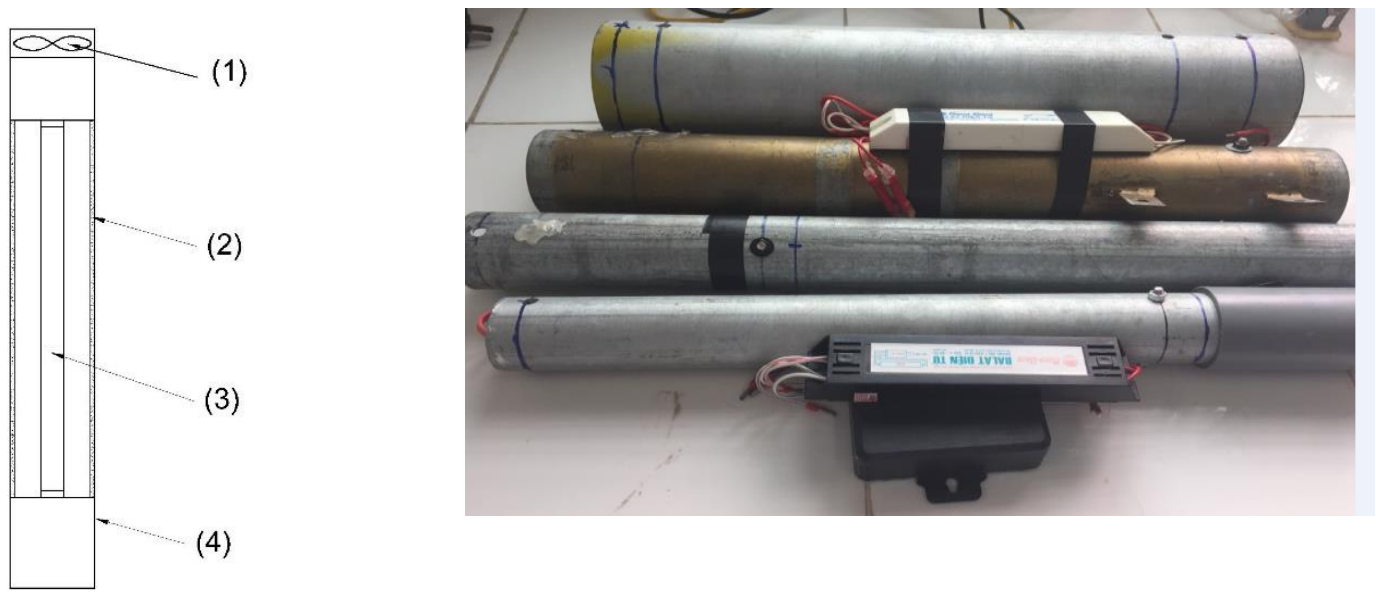

Figure 3. (a) Photocatalytic device: (1) fan, (2) catalytic coated glass fiber sheet, (3) UV-A lamp, and (4) stainless steel tube; (b) Real image of photocatalytic devices

Parallel tests in a closed chamber with the treatment device and a controlled chamber without the device were conducted. Incense (N3) was firstly burned up to the concentration of TVOCs approximately of $1,045 \mathrm{ppb}$ and then stopped burning. The analytical device was turned on for about 15 min to get ready. The pollutant concentration was then recorded in triplicates every $15 \mathrm{~min}$ for a total of at least $180 \mathrm{~min}$. To test the effect of the weight of photocatalyst, 1.0, 1.5 , and $2.0 \mathrm{~g}$ of $\mathrm{Zn}_{1.0} / \mathrm{TNTs}_{500}$ was used to prepare the solution for dip coating process of the glass fiber sheet as mentioned above. and the device diameter of $60 \mathrm{~mm}$. To test the effect of type of photocatalyst, five types of photocatalyst differed in the amount of $\mathrm{Zn}$ doped and calcination temperatures $\left(\mathrm{P}_{25} 5_{500}, \quad \mathrm{Zn}_{0.5} / \mathrm{TNT}_{\mathrm{s} 400}, \quad \mathrm{Zn}_{1.0} / \mathrm{TNTs}_{400}, \quad \mathrm{Zn}_{0.5} / \mathrm{TNTs}_{500}, \quad\right.$ and $\mathrm{Zn}_{1.0} / \mathrm{TNTs500}$ ) were then applied for the treatment. In the final step, the effect of device diameter was investigated with the diameter varied from $42,49,60$, and $90 \mathrm{~mm}$. The average chamber temperature and humidity were $31.9 \pm 4.6^{\circ} \mathrm{C}$ and $76.7 \pm 12.1 \%$, respectively.

\section{Results and Discussion}

\section{Field Investigation}

\section{Phase 1: Pollutants Concentration at Five Pagodas}

Observation from pagodas revealed that raw and perfume incenses were the two most commonly used in the five pagodas. The incense used was found in the form of sticks or coils. Stick form was usually burned in the outside area while the coil form was in the main area. There were 20 to 25 locations for burning incense for each pagoda. Most Buddhists and other visitors went to the pagodas had the demand for incense offering at least one stick per each incense pot.

Figure 4 showed the images taken at the time of the investigation. In reality, many Buddhists and other visitors at the pagodas burned a bunch of incense for one visiting time (at least 25 sticks/ a bunch). The number of visitors and therefore the number of incense burned on 
holidays and full moon days was higher than normal days. The atmosphere in the pagodas on these days was stuffy even in the pagodas with large space. To reduce the smoke, avoid affecting the air quality, and reduce the risk of fire, the burning incense sticks and the remaining parts after burning were collected and gathered to the incinerator in the pagodas to burn off the rest. In addition, at pagoda $\mathrm{A}$ there was a layout of the banners at the incense burning sites that each person should only burn up to six sticks per time and do not burn incense in the main hall of the pagoda.

(a)

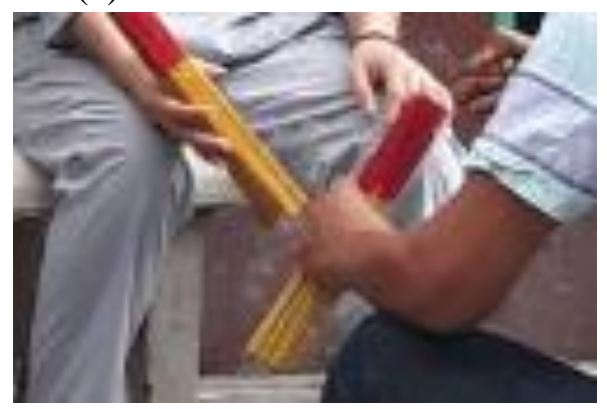

(b)

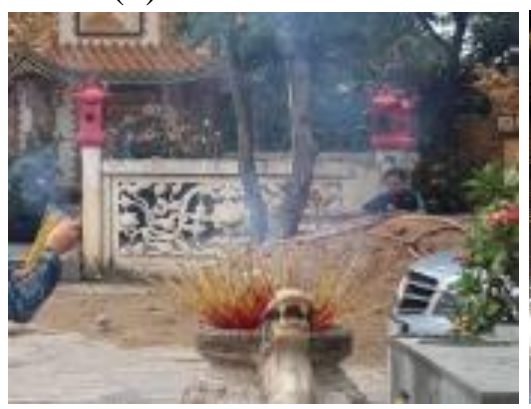

(c)

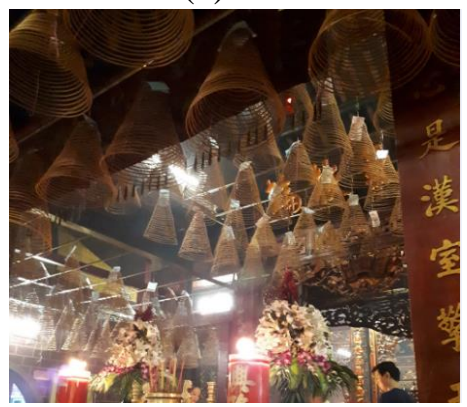

Figure 4. Incense burning in the pagoda: (a) bunches of incense; (b) an incense pot located outsite pagoda; (c) an incense pot located insite pagoda

For monitoring the air pollutants, we selected the locations in the pagodas which were crowded with Buddhists and visitors and a large number of incense lit. The average concentration of pollutants from five pagodas (P-A, P-B, P-C, P-D, and P-E) is illustrated in Figure 5. As can be seen, PM2.5 and PM10 in the five pagodas ranged from 752 to $2,137 \mu \mathrm{g} / \mathrm{m}^{3}$ and 924 to $2,871 \mu \mathrm{g} / \mathrm{m}^{3}$, respectively, which were mostly higher than PM2.5 recorded at two temples in Hong Kong [9]. Since there is no standard for indoor air quality in Vietnam, we compared the concentration of PM2.5 with the allowable values recommended from references. Clearly, PM2.5 in five pagodas exceeded the standards from the US (65 $\mu \mathrm{g} / \mathrm{m}^{3}$ for $24 \mathrm{~h}$ average) (ASHRE, US EPA), Canada (40 $\mu \mathrm{g} / \mathrm{m}^{3}-8 \mathrm{~h}$ average, $100 \mu \mathrm{g} / \mathrm{m}^{3}-1 \mathrm{~h}$ average), and also WHO (25 $\mu \mathrm{g} / \mathrm{m}^{3}$ as $24 \mathrm{~h}$ average). Similarly, PM10 from these pagodas were over the standards and guidelines from China and the US $\left(150 \mu \mathrm{g} / \mathrm{m}^{3}-24 \mathrm{~h}\right.$ average), WHO (50 $\mu \mathrm{g} / \mathrm{m}^{3}-24 \mathrm{~h}$ average), Malaysia, Hong Kong, Finland (150, 180 and less than $20 \mu \mathrm{g} / \mathrm{m}^{3}-8 \mathrm{~h}$ average, respectively), and Australia (90 $\mu \mathrm{g} / \mathrm{m}^{3}-1 \mathrm{~h}$ average). However, PM10 was still under the standards from Germany ( $4 \mathrm{mg} / \mathrm{m}^{3}-8 \mathrm{~h}$ average) and the US $\left(10 \mathrm{mg} / \mathrm{m}^{3}-8 \mathrm{~h}\right.$ average). According to the color indicator of health effect level corresponding to the concentration as given by the analytical instrument, both PM2.5 and PM10 were highly over from the dangerous thresholds (i.e. "gray color" corresponding to $250-500 \mathrm{mg} / \mathrm{m}^{3}$ for PM2.5 and $424-604$ for PM10 mg/m 3 ). Since PM2.5 is directly linked to respiratory illnesses and infections such as asthma, cardiovascular and respiratory diseases, including lung cancer, while PM10 is less toxic than PM2.5 but still can cause the symptoms of respiratory infections and irritations and if exposure is long enough may cause pulmonary and cardiovascular diseases as well as lung cancer, the results in concentration of two types of particles in pagodas affirmed that the concentration of particles in incense would directly affect the human health. 
The highest TVOCs concentration was 1,108 ppb at Pagodas $\mathrm{C}$ and the lowest value was $621 \mathrm{ppb}$ at Pagodas $\mathrm{A}$, which is in the orange indicator level (corresponding to the concentration of 660-2,200 ppb) recommended avoiding exposure and the air environment should be ventilated. The concentration of TVOCs exceeded the permitted standard for $24 \mathrm{~h}$ average of the US (140 ppb), WHO (48 ppb), and China (490 ppb in terms of HCHO) [14]. The range of TVOCs in Vietnamese pagodas in this study was lower than that found around incense burners but higher than that at the worship room in temples located in China [11]. VOCs include various types of organic compounds that can irritate the eyes, nose, and skin, resulting in shortness of breath, headache, fatigue, nausea, and dizziness. High concentrations of VOCs can damage the lungs, as well as harm the liver, kidneys, or central nervous system. Some VOCs are suspected to cause cancer for humans and have been shown to cause cancer for animals. The health effects caused by VOCs depend on the concentration and duration of exposure. In addition, VOCs are also one of the causes of photochemical haze.

This study also recorded the $\mathrm{CO}_{2}$ concentration in the pagodas which was from 866 to 2,967 ppm. Again, most of these values were over the guidelines and standards from China (1,000 ppm-24 h average) and Kuwait (1,400 ppm-24 h average) but still under the the allowable values for expose in shorter times (e.g. in Hong Kong: 30,000 ppm in 15 min average and 3,500 ppm in $1 \mathrm{~h}$ average; in Australia: 30,000 ppm as 15 min average, in Kuwait: 5,000 ppm for $1 \mathrm{~h}$ average [21]).

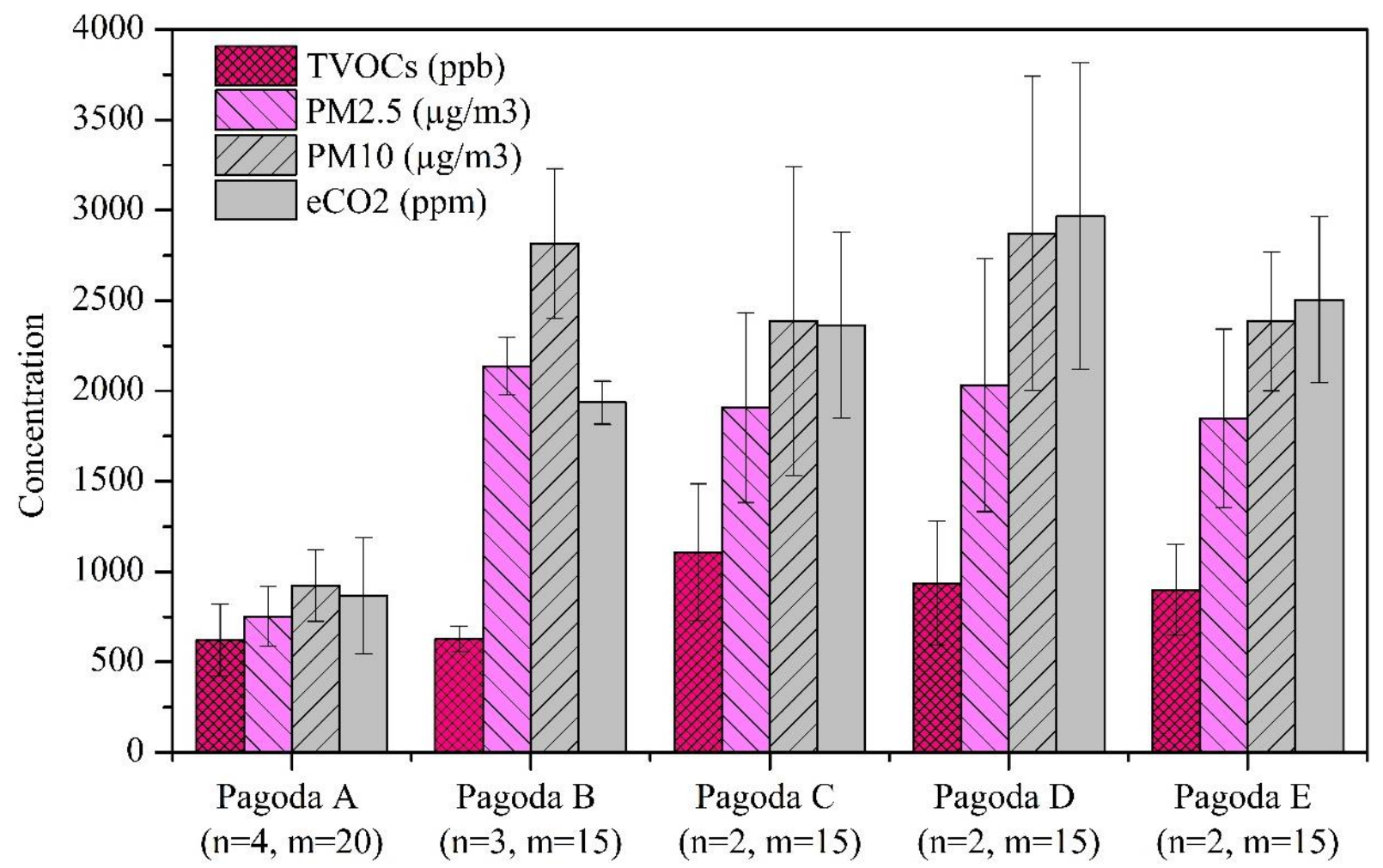

Figure 5. The average concentration of TVOCs, PM2.5, $\mathrm{PM} 10, \mathrm{eCO}_{2}$ at 5 pagodas (Columns depict average values from (n) days with (m) times of measurement/day, error bars show the corresponding standard deviations). 
Phase 2: Investigate the Variation in Pollutants on Different Days in P-A Pagoda

P-A pagoda was selected for the next survey due to its convenience in sampling. This survey was conducted on different days in the lunar month (the beginning of the month, the end of the month, the full moon and weekdays). The steps to conducting the second phase survey were similar to the first round with each measurement lasting for $75-100 \mathrm{~min}$, recording every 5 min.

As can be seen from Figure 6, the emission level of TVOC, PM10 and PM2.5 increased by the order of weekdays, the end of month, full moon days and then the first of month which is due to the increase of number of visitors as we observed the number of visitor was more crowded on on the first of month and full moon days compared to those on weekdays and the end of month. PM10 and PM2.5 of the days varied in the range of 561-1,589 $\mu \mathrm{g} / \mathrm{m}^{3}$ and $446-$ $1,175 \mu \mathrm{g} / \mathrm{m}^{3}$, respectively, which was lower than the standard of indoor air of Canada [11] but still exceeded the danger level in the color indicator according to the Addwii device. The highest and lowest concentration of VOCs was 1,092 ppb at the first of the month and $97 \mathrm{ppb}$ during weekdays, respectively. While TVOCs concentration in the first of month and full moon days exceeded the permitted standard (490 ppb), this parameter on end of month and weekdays was lower than the standard.

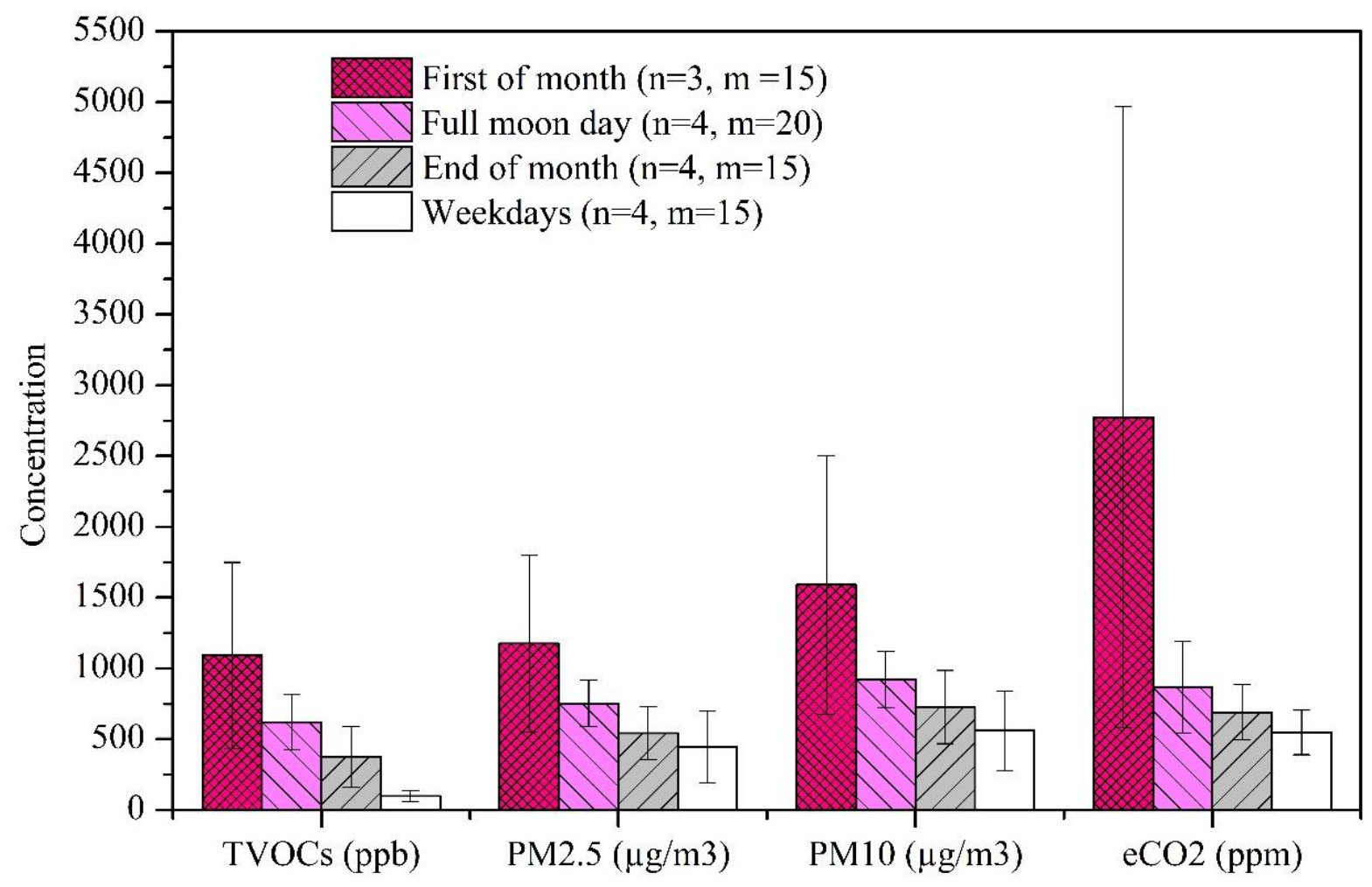

Figure 6. The average concentration of pollutants at P-A pagoda (Columns depict average values from (n) days with (m) measurements/day, error bars show the corresponding standard deviations) 


\section{Investigate the Pollutants Emission by Burning Incense in the Room}

Since the room for testing pollutant emission was closed, pollutants tend to accumulate and their concentration increases by time. The results of PM2.5, PM10 and VOCs variation by time are presented in Figure 7 and the average values are given in Figure 8. Most incenses were burned out for about 75 min except N7 due to its high weight and long length. In general, pollutant concentrations fluctuated during the observation time which would be due to the no uniform of incense material for whole stick length as they were manually made. As can be seen from Figure 7, PM2.5 and PM10 of incenses varied from 278-911 and 360-1,158 $\mu \mathrm{g} / \mathrm{m}^{3}$, respectively, which were in the range from hazardous to dangerous indicator levels. For both PM2.5 and PM10, N1 and N7 as non-containing chemical incenses generated similar concentrations and both higher than the remaining incenses. Among seven types of incense, N6 black incense containing carbon components generated the lowest PM10 and PM2.5 dust content. The ranges of PM2.5 and PM10 concentration levels from seven types of incense in this study were in the ranges found from Jetter et al. [2] and Lee and Wang [6] but some our types of incense generated lower values of PM 2.5 compared to Lui et al. [7]. It is important to note that this comparison should be used for reference only since the volume of room and experiment conditions were different in these studies.
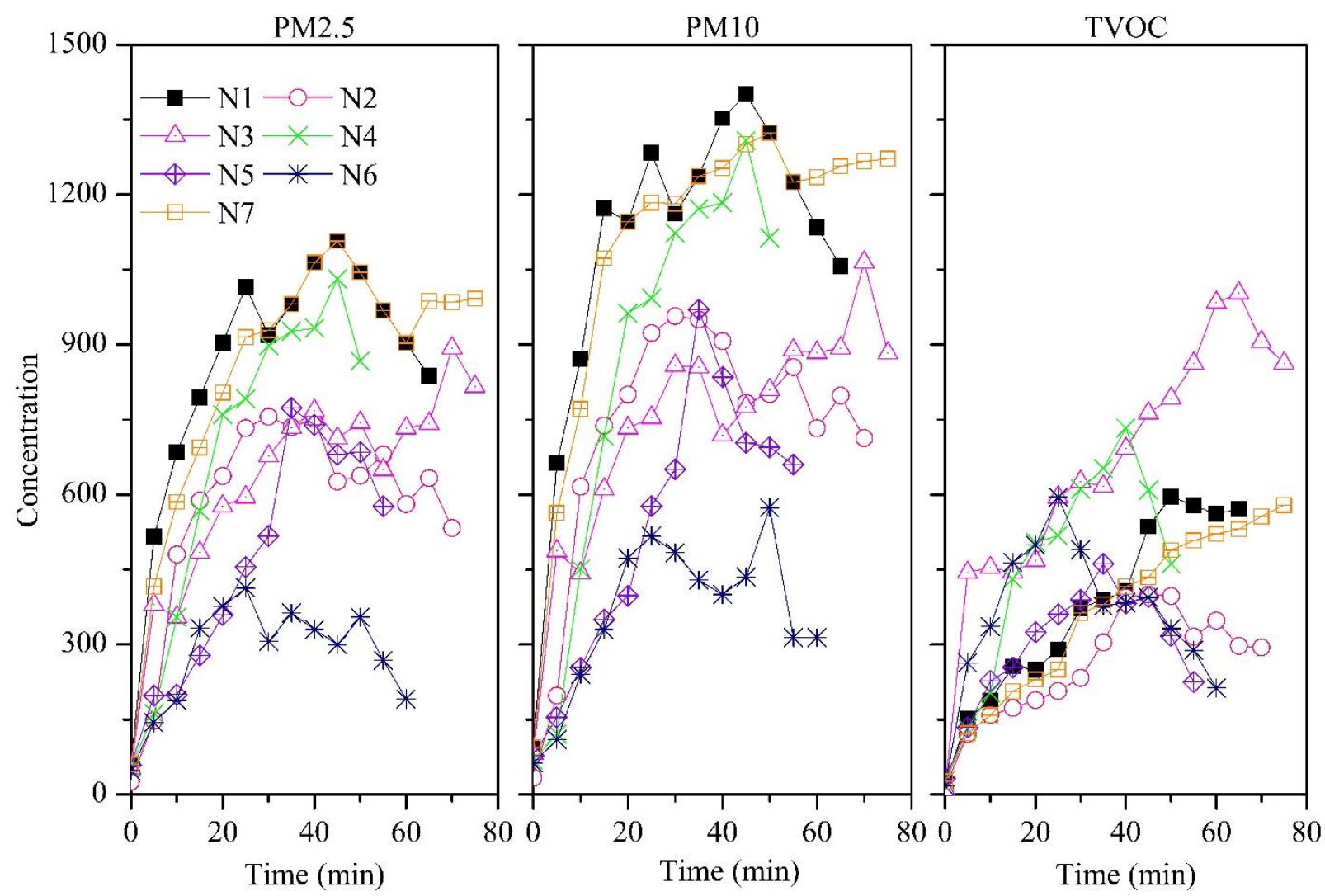

Figure 7. The variation by time of PM2.5 $\left(\mu \mathrm{g} / \mathrm{m}^{3}\right)$, PM10 $\left(\mu \mathrm{g} / \mathrm{m}^{3}\right)$, and TVOCs $(\mathrm{ppb})$ concentrations 


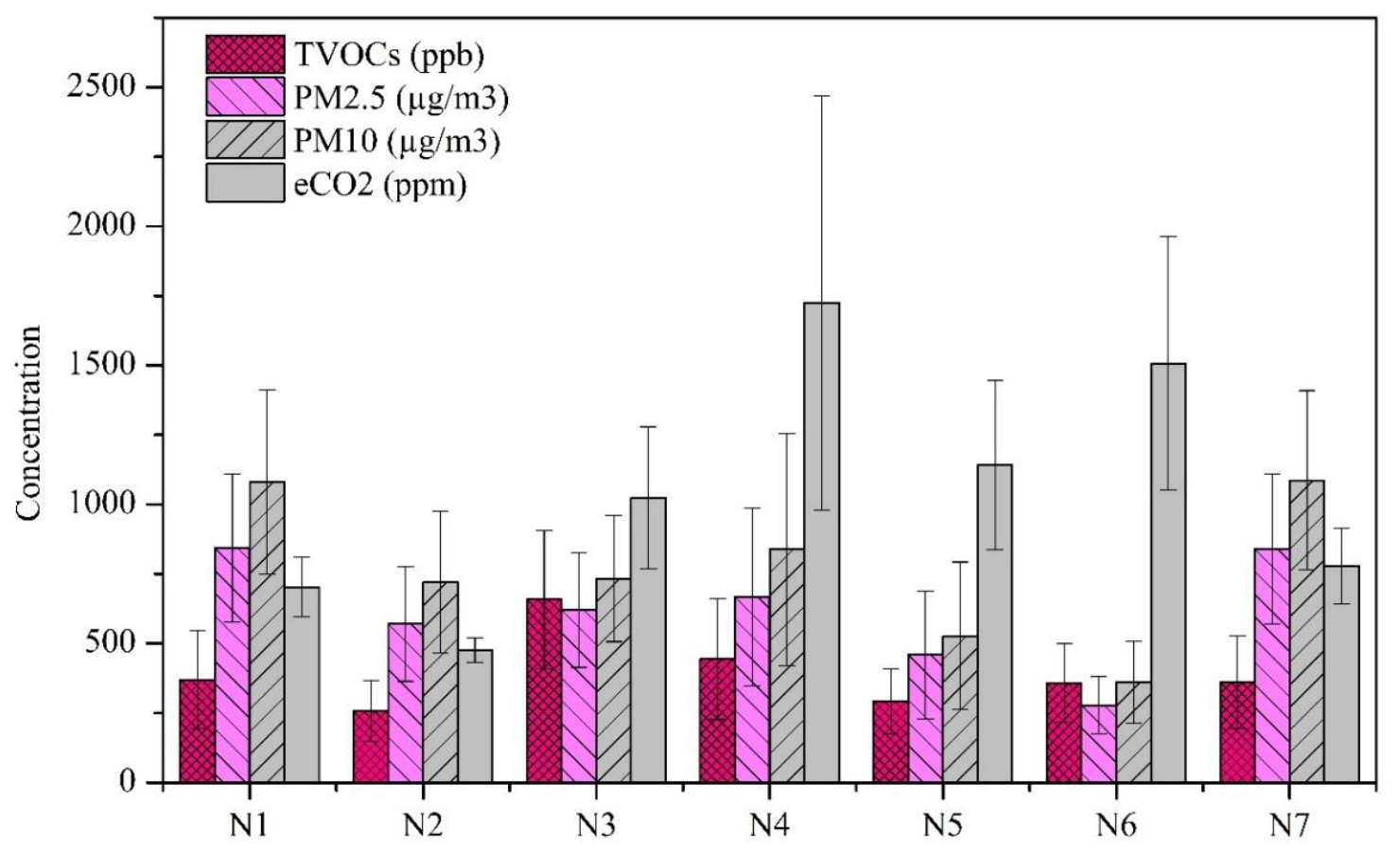

Figure 8. The average concentration of pollutants of each type of incense (Columns depict average values from 15 times of measurement within 75 min of incense burning, error bars show the corresponding standard deviations)

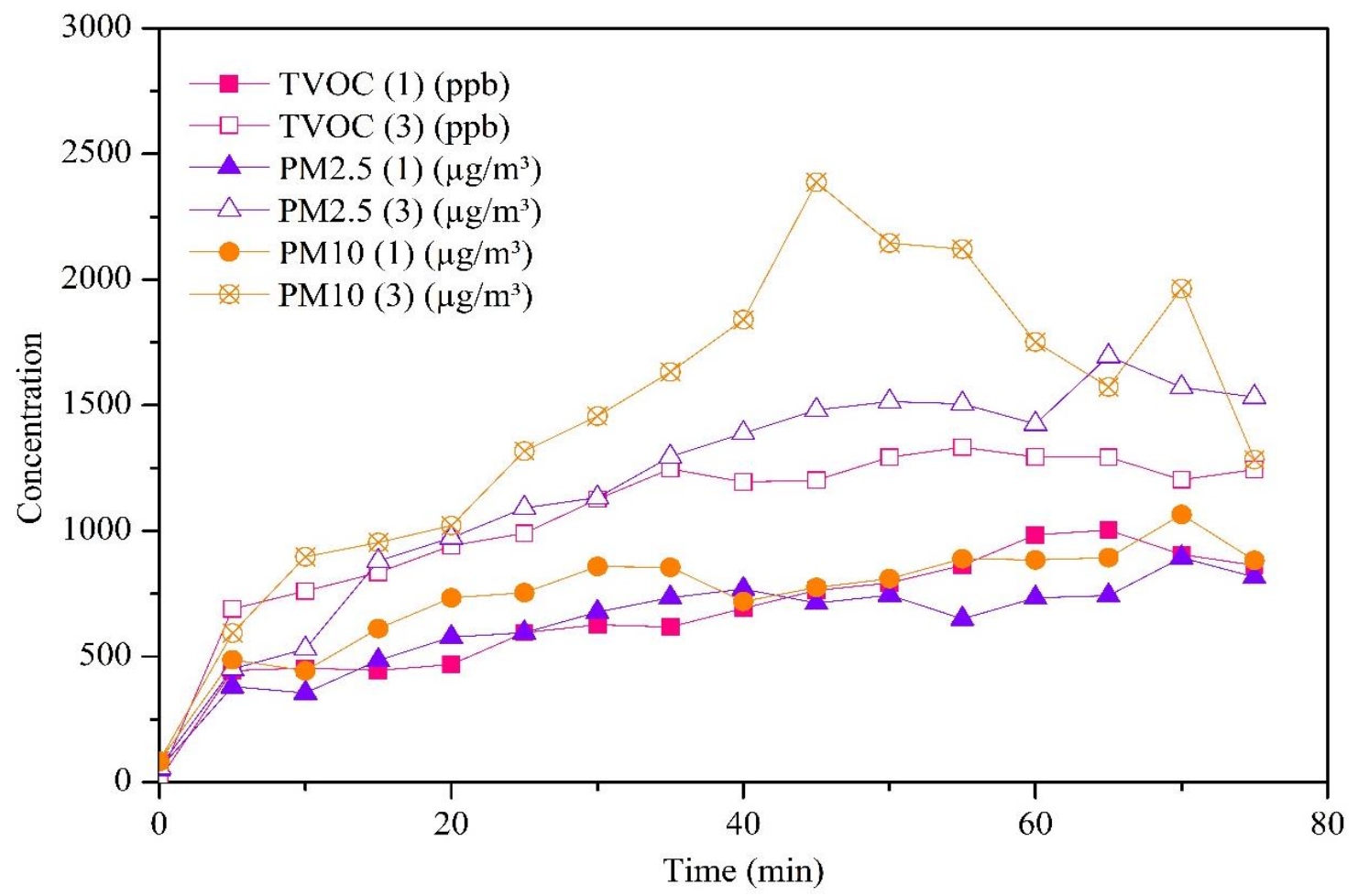

Figure 9. Comparison of pollutants concentration generated by burning one (1) and three (3) sticks of $\mathrm{N} 3$ 
TVOCs concentration generated by seven types of incense was from 256-658 ppb in which cinnamon incense N3 generated the highest concentration and was then chosen in the next experiment. Since people in Vietnam also regularly burn 3 incense stick/time, three sticks of N3 were burned simultaneously and TVOCs emission concentration was measured every five minutes. As can be seen from Figure 9, the concentration of pollutants generated by burning 3 sticks of N3 was higher than that of burning 1 incense stick about 1.80 times for PM10, 1.75 times for PM2.5, and 1.53 times for VOCs. The average concentration of TVOCs was 1,045 ppb which was 2.13 times higher than the permitted value (490 ppb).

\section{Investigate TVOCs Removal Efficiency by Photocatalytic Treatment Device}

The results from room and chamber tests showed the major pollutants from the incense burning are dust (e.g., PM10 and PM2.5) and VOCs (e.g. TVOCs). In the market, there are several commercial air purifiers using coarse and HEPA filters, meaning that they can effectively remove the particles (i.e. dust) in the air. Also, there are some air purifiers that include activated carbon for VOCs adsorption, which needs to be replaced after saturation. Therefore, this study focused on the removal of VOCs by oxidation, in which the catalyst could have much longer lifetime than the adsorbent. Moreover, the incorporation of a dust filter and a catalytic system is feasible without major problems in design and calculation, which could be commercialized in the near future.

It is generally known that photocatalyst (e.g. $\mathrm{TiO}_{2}$ ) under $\mathrm{UV}$ light irradiation would generate $\bullet \mathrm{OH}$ or superoxide $\left(\bullet \mathrm{O}_{2}^{-}\right)$radicals which oxidizes VOC to $\mathrm{H}_{2} \mathrm{O}, \mathrm{CO}_{2}$ or other organic harmless substances, by following reactions [22]:

$$
\begin{aligned}
& \mathrm{TiO}_{2}+\mathrm{hv} \rightarrow \mathrm{hvB}^{+}+\mathrm{eCB}^{-} \\
& \mathrm{TiO}_{2}+\mathrm{hvB}^{+}+\mathrm{H}_{2} \mathrm{O} \rightarrow \bullet \mathrm{OH}+\mathrm{H}^{+} \\
& \mathrm{O}_{2}+\mathrm{e}_{\mathrm{CB}}^{-} \rightarrow \bullet \mathrm{O}_{2}^{-}
\end{aligned}
$$

We hence proposed a treatment unit applied $\mathrm{TiO}_{2}$ photocatalyst for oxidation of TVOC in smoke from incense burning. Effects of the amount and type of photocatalyst and the diameter of the device treatment were tested and discussed as follows.

\section{Effect of Photocatalyst Amount on VOCs Removal Efficiency}

In this experiment, N3 was firstly burned up to the concentration of TVOCs approximately 1,045 ppb then stopped. TVOCs generated was treated by a treatment device with a diameter of 60 $\mathrm{mm}$ and the weight of photocatalyst $\mathrm{Zn}_{1.0} / \mathrm{TNT}_{500}$ varied from 1.0, 1.5 and $2.0 \mathrm{~g}$. As can be seen from Figure 10(a), TVOCs concentration in control chamber without the treatment device was reduced at a certain level $(23.06 \%)$ after 180 min which could be due to (i) photolysis of TVOC by light available inside and outside the chamber, possibly due to the high reactivity classes of hydrocarbons and VOCs (e.g., aldehydes, terpenes, alkenes, and esthers); (ii) the adsorption of TVOCs on the inside surface of the chamber; and (iii) the leaking of TVOCs. Compared to the control chamber, the chamber containing treatment equipment proved its 
capability of handling TVOCs. When the mass of catalyst varied, the trends of TVOCs variation were quite similar for $1.0,1.5$ and $2.0 \mathrm{~g}$ of $\mathrm{Zn}_{1.0} / \mathrm{TNTs} 500$. After $180 \mathrm{~min}$ of treatment, nearly similar efficiencies were achieved from three masses of photocatalyst $(39.68 \%$ by $1.0 \mathrm{~g}, 39.74 \%$ by $1.5 \mathrm{~g}$ and $39.93 \%$ by $2.0 \mathrm{~g}$ ). Therefore, $1.0 \mathrm{~g}$ of the photocatalyst was applied for follow-up experiments.

(a)

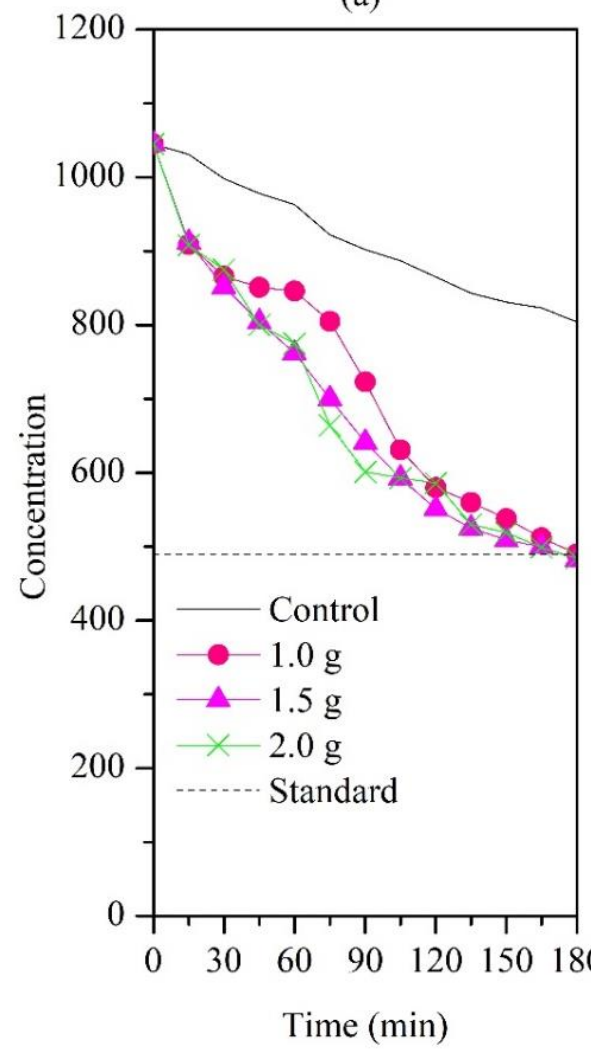

(b)

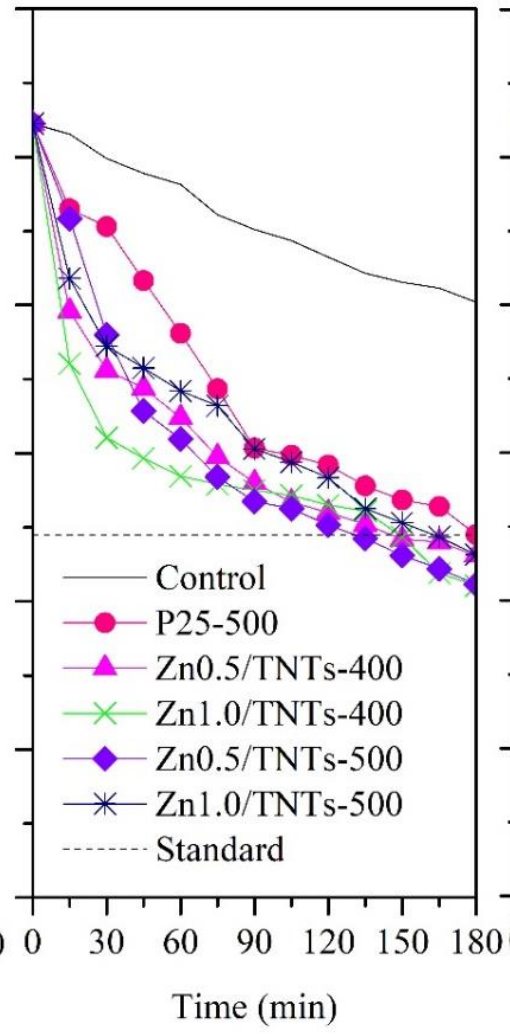

(c)

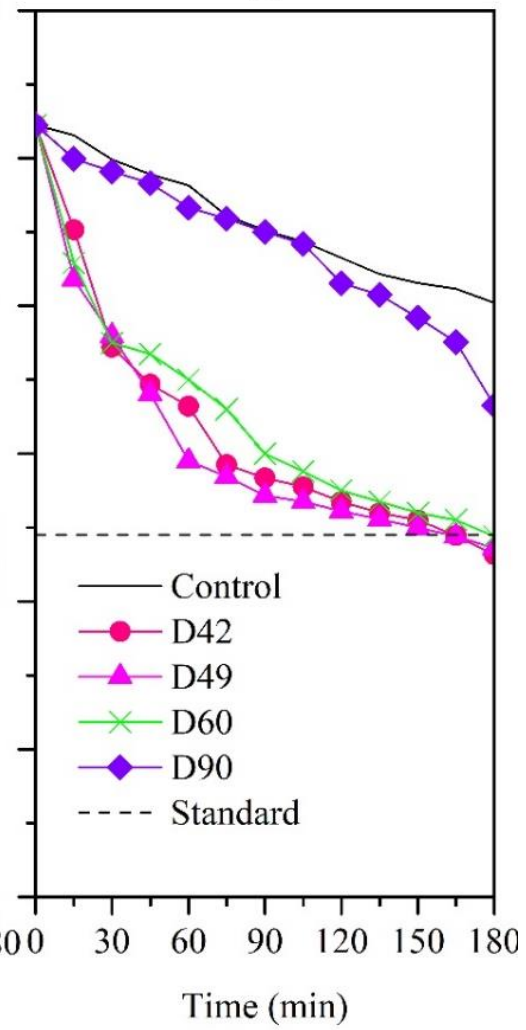

Figure 10. The change of TVOCs concentration by time using treatment device with different (a) photocatalyst masses, (b) photocatalysts, and (c) device diameters

\section{Effect of Type of Photocatalysts on TVOCs Treatment}

Annealing at high temperature (i.e. calcination) is an option to increase the crystallinity of $\mathrm{TiO}_{2}$ but may cause a reduction in surface area due to the disruption of the pore of the material as well as changing from anatase to rutile phase with lower photocatalytic activity [23-25]. Liu et al. [26] mentioned that doping ions or oxides on $\mathrm{TiO}_{2}$ can modify the band gap or act as charge separators of the electron-hole pair of the photocatalyst, thus enhancing the photocatalytic activity. However, there was an optimum content of $\mathrm{Zn}$ and doping over this value may cause a certain amount of $\mathrm{Zn}$ not to diffuse into the $\mathrm{TiO}_{2}$ lattice, but deposit on the surface of $\mathrm{TiO}_{2}$ which lessens the specific area of the material hence reduces their photocatalytic activity. Therefore, it is necessary to determine the best condition of calcination and the suitable zinc content for obtaining the highest VOCs removal efficiency. In this study, the TNTs precursor was doped by $\mathrm{Zn}$ at different weight percentages $(0.5-1.0 \%)$ and then calcined at different temperatures $\left(400\right.$ or $\left.500^{\circ} \mathrm{C}\right)$ created photocatalyst, i.e. $\mathrm{Zn}_{0.5} / \mathrm{TNT}_{\mathrm{s} 400,} \mathrm{Zn}_{1.0} / \mathrm{TNTs}_{400}$, 
$\mathrm{Zn}_{0.5} / \mathrm{TNTs}_{500}$, or $\mathrm{Zn}_{1.0} / \mathrm{TNT}_{500}$ ). To test the photocatalytic activity of the photocatalyst, the treatment device with a diameter of $49 \mathrm{~mm}$ containing $1 \mathrm{~g}$ photocatalysts was used to treat TVOCs. As can be seen in Figure 10(b), all titanium nanotube photocatalysts provided higher removal efficiencies of TVOCs than that of P25500 which proved the advantage of titanium nanotube structure. Among titanium nanotube, $\mathrm{Zn}_{1} / \mathrm{TNTs} 400$ showed the fastest treatment rate for $90 \mathrm{~min}$ at the beginning of treatment. After $180 \mathrm{~min}$ of treatment, $\mathrm{Zn}_{1} / \mathrm{TNTs} 400$ and Zno.5/TNTs500 provided similar removal efficiencies which were better than those achieved by other photocatalysts. To decrease TVOCs concentration to the allowable value (490 ppb), the treatment times were $135 \mathrm{~min}$ for $\mathrm{Zn}_{0.5} / \mathrm{TNTs}_{500}$ and $150 \mathrm{~min}$ for $\mathrm{Zn}_{1} / \mathrm{TNTs}_{400}$, while the remaining photocatalysts needed more than $165 \mathrm{~min}$. It is concluded that the photocatalyst of Zn0.5/TNTs500 with $0.5 \%$ zinc and calcined at $500{ }^{\circ} \mathrm{C}$, was the most suitable material and it will be used for further experiments.

\section{Effect of Diameter of Treatment Device on TVOCs Removal}

In this experiment, the treatment devices with different diameters $(42,49,60$, or $90 \mathrm{~mm})$ contained $1 \mathrm{~g}$ of $\mathrm{Zn}_{0.5} / \mathrm{TNTs}_{500}$ was used to treat TVOCs. As can be seen from Figure 10(c), the device with the diameter of $90 \mathrm{~mm}$ provided the trend of TVOCs concentration reduction quite similar to the trend found in the control chamber. When the diameters of the devices reduced from 60 to $42 \mathrm{~mm}$, their performances of TVOCs removal were slightly increased $(39.67 \%$ to $42.16 \%$ ) and significantly better than the performance provided by the $90 \mathrm{~mm}$ diameter device $(18.22 \%)$. It can be explained that when the diameter reduced the distance between the UV light and photocatalyst surface reduced which led to the activation of photocatalyst as well as the mass transferring of VOCs to photocatalyst surface more effective, hence increase the oxidation efficiency of TVOCs. However, it is also needed to note that since these devices using the same fans, the airflow passing through the devices was similar. Reducing in the diameter led to the increase of air velocity and therefore lowed down the retention time of VOCs on the device. It may be the reason that we only achieved a slight increase in TVOCs removal efficiency when the diameter was reduced from 60 to $42 \mathrm{~mm}$.

It is noted that the test was only applied in a chamber with low volume of air. In order to evaluate the feasibility of the device for practical application, the device needs to be tested in a real room. In that case, the design of the device need to be improved and the position of the device in the room need to be carefully considered to make sure as much polluted air as possible that pass through the device for effective treatment of VOCs.

\section{Conclusions}

Field investigation of pollutants emitted by burning incense in five pagodas in Vietnam revealed the serious air pollution (TVOCs: $625-1,108 \mathrm{ppb}$, PM2.5: 1,175-2,137 $\mu \mathrm{g} / \mathrm{m}^{3}$, and PM10: 1,589$2,871 \mu \mathrm{g} / \mathrm{m}^{3}$ ) and raised the concern of their negative effects on human health. Monitoring pollutants concentration for different days in a pagoda showed the beginning day of the month seemed to be polluted the most. Among seven types of incense commonly found in the Vietnam market, burning cinnamon incense in the room generated the highest concentration of TVOCs while raw and coil incenses emitted the highest concentration of PM2.5 and PM10. Application of different photocatalysts in a device for TVOCs treatment found that zinc salt-impregnated 
titanium dioxide $\left(0.5 \%(\mathrm{w} / \mathrm{w})\right.$ of $\mathrm{Zn}$, calcined at $\left.500^{\circ} \mathrm{C}\right)$ removed $48.13 \%$ of TVOCs for 180 min and this photocatalyst required $135 \mathrm{~min}$ of treatment to reach the allowable level (490 ppb). TVOCs removal efficiency insignificantly changed when the device diameter increased from 42 to $60 \mathrm{~mm}$, but obviously lowed if the diameter was $90 \mathrm{~mm}$. Application of photocatalytic device for TVOCs removal in this study is an initially successful approach to address VOCs emission from burning incense.

Since data collected in this study was limited due to the time restriction, future study should be conducted for longer duration to find the difference in the incenses smoke pollutants in pagodas between different types of days and different months of a year, expanded also for occasions such as festivals and Lunar new year. Furthermore, though the photocatalyst device presented a quite satisfied removal efficiency, the treatment process was still required a long time $(135 \mathrm{~min})$ to let the TVOC concentration reach the allowable standard. Hence, futher investigation to improve the removal efficiency is needed, in which applying more than one device/module for the treatment would be a good suggestion. Study about the durability over time of the device for the treatment and application of thee device in real room is also important to conclude its feasibility for real cases application.

\section{Acknowledgement}

This research is funded by Ho Chi Minh City University of Technology - VNU-HCM under grant number To-MTTN-2018-09.

\section{References}

[1] B. Wang, S. Lee, K.F. Ho, and Y.M. Kang, "Characteristics of emissions of air pollutants from burning of incense in HK temples," Science of the Total Environment, Vol. 377, pp. 5260, 2007.

[2] J.J. Jetter, Z. Guo, J.A. McBrian, and M.R. Flynn, "Characterization of emissions from burning incense," Science of the Total Environment, Vol. 295, No. 1, pp. 51-67, 2002.

[3] S. Bootdee, S. Chantara, and T. Prapamontol, "Determination of PM2.5 and polycyclic aromatic hydrocarbons from incense burning emission at shrine for health risk assessment," Atmospheric Pollution Research, Vol. 7, No. 4, pp. 680-689, 2016.

[4] T.-T. Yang, Y.M. Kuo, H.F. Hung, R.H. Shie, and P. Chang, "Gas pollutant emissions from smoldering incense using FTIR," Aerosol and Air Quality Research, Vol. 7, No. 3, pp. 417-431, 2007.

[5] T.-T. Yang, S.-C. Ho, L.-T. Chuang, H.-C. Chuang, Y.-T. Li, and J.-J. Wu, "Characterization of particulate-phase polycyclic aromatic hydrocarbons emitted from incense burning and their bioreactivity in RAW264.7 macrophage," Environmental Pollution, Vol. 220, pp. 1190-1198, 2017.

[6] S.-C. Lee, and B. Wang, "Characteristics of emissions of air pollutants from burning of incense in a large environmental chamber," Atmospheric Environment, Vol. 38, No. 7, pp. 941951, 2004.

[7] K.H. Lui, B.A.M. Bandowe, S.S.H. Ho, H.-C. Chuang, J.-J. Cao, K.-J. Chuang, S.C. Lee, D. $\mathrm{Hu}$, and K.F. Ho, "Characterization of chemical components and bioreactivity of fine particulate matter (PM2.5) during incense burning," Environmental pollution (Barking, Essex: 1987), Vol. 213, pp. 524-532, 2016. 
[8] N.N.B. Chinh, Y. Fujii, T.T. Hien, and N. Takenaka, "Characteristics of gas phase carbonyl emission and excess risk from incense stick burning," Water, Air, \& Soil Pollution, Vol. 231, No. 6, pp. 297, 2020.

[9] B. Wang, S.C. Lee, K.F. Ho, and Y.M. Kang, "Characteristics of emissions of air pollutants from burning of incense in temples, Hong Kong," Science of the Total Environment, Vol. 377, No. 1, pp. 52-60, 2007.

[10] P. Navasumrit, M. Arayasiri, O.M.T. Hiang, M. Leechawengwongs, J. Promvijit, S. Choonvisase, S. Chantchaemsai, N. Nakngam, C. Mahidol, and M. Ruchirawat, "Potential health effects of exposure to carcinogenic compounds in incense smoke in temple workers," Chemico-Biological Interactions, Vol. 173, No. 1, pp. 19-31, 2008.

[11] J. Zhang, W. Chen, J. Li, S. Yu, and W. Zhao, "VOCs and particulate pollution due to incense burning in temples, China," Procedia Engineering, Vol. 121, pp. 992-1000, 2015.

[12] J.-R. He, D.-M. Wei, F.-F. Chan, Y.-Z. Luan, S. Tu, J.-H. Lu, W.-D. Li, M.-Y. Yuan, N.N. Chen, Q.-Z. Chen, K.B.H. Lam, K.K. Cheng, H.-M. Xia, and X. Qiu, "Associations between maternal exposure to incense burning and blood pressure during pregnancy," Science of the Total Environment, Vol. 610-611, pp. 1421-1427, 2018.

[13] R. Zhou, Q. An, X.W. Pan, B. Yang, J. Hu, and Y.H. Wang, "Higher cytotoxicity and genotoxicity of burning incense than cigarette," Environmental Chemistry Letters, Vol. 13, No. 4, pp. 465-471, 2015.

[14] A. Luengas, A. Barona, C. Hort, G. Gallastegui, V. Platel, and A. Elias, "A review of indoor air treatment technologies," Reviews in Environmental Science and Bio/Technology, Vol. 14, No. 3, pp. 499-522, 2015.

[15] C.-R. Yang, Y.-S. Peng, Y.-F. Chang, and Y.I. Tsai, "Reducing emissions of air pollutants from incense burning with the addition of nanoscale calcium carbonate," Scientific Research and Essays, Vol. 6, pp. 2011.

[16] N.H. Nguyen, and H. Bai, "Photocatalytic removal of $\mathrm{NO}$ and $\mathrm{NO}_{2}$ using titania nanotubes synthesized by hydrothermal method," Journal of Environmental Sciences, Vol. 26, No. 5, pp. 1180-1187, 2014.

[17] T. Kasuga, M. Hiramatsu, A. Hoson, T. Sekino, and K. Niihara, "Formation of titanium oxide nanotube," Langmuir, Vol. 14, No. 12, pp. 3160-3163, 1998.

[18] C.C. Tsai, and H.S. Teng, "Structural features of nanotubes synthesized from $\mathrm{NaOH}$ treatment on $\mathrm{TiO}_{2}$ with different post-treatments," Chemistry of Materials, Vol. 18, No. 2, pp. 367-373, 2006.

[19] N.H. Nguyen, H.-Y. Wu, and H. Bai, "Photocatalytic reduction of $\mathrm{NO}_{2}$ and $\mathrm{CO}_{2}$ using molybdenum-doped titania nanotubes," Chemical Engineering Journal, Vol. 269, No. 0, pp. 6066, 2015.

[20] N.H.M. Linh, T.T.M. Linh, V.T.T. Thuy, and N.N. Huy, "Metal doped titanium dioxide for removal of formaldehyde vapor "Journal of Transportation Science and Technology, Vol. 32, pp. 53-59, 2019.

[21] S.A. Abdul-Wahab, S. Chin Fah En, A. Elkamel, L. Ahmadi, and K. Yetilmezsoy, "A review of standards and guidelines set by international bodies for the parameters of indoor air quality," Atmospheric Pollution Research, Vol. 6, No. 5, pp. 751-767, 2015.

[22] Y. Huang, S.S. Ho, Y. Lu, R. Niu, L. Xu, J. Cao, and S. Lee, "Removal of indoor volatile organic compounds via photocatalytic oxidation: a short review and prospect," Molecules, Vol. 21, No. 1, pp. 56, 2016. 
[23] H.H. Ou, and S.L. Lo, "Review of titania nanotubes synthesized via the hydrothermal treatment: fabrication, modification, and application," Separation and Purification Technology, Vol. 58, No. 1, pp. 179-191, 2007.

[24] C.L. Wong, Y.N. Tan, and A.R. Mohamed, "A review on the formation of titania nanotube photocatalysts by hydrothermal treatment," Journal of Environmental Management, Vol. 92, No. 7, pp. 1669-1680, 2011.

[25] N. Liu, X. Chen, J. Zhang, and J.W. Schwank, "A review on $\mathrm{TiO}_{2}$-based nanotubes synthesized via hydrothermal method: formation mechanism, structure modification, and photocatalytic applications," Catalysis Today, Vol. 225, pp. 34-51, 2014.

[26] G. Liu, X. Zhang, Y. Xu, X. Niu, L. Zheng, and X. Ding, "The preparation of Zn ${ }^{2+}$-doped $\mathrm{TiO}_{2}$ nanoparticles by sol-gel and solid phase reaction methods respectively and their photocatalytic activities," Chemosphere, Vol. 59, No. 9, pp. 1367-1371, 2005. 